(2) Open Access Full Text Article

\title{
Anxiety in adolescents: Update on its diagnosis and treatment for primary care providers
}

This article was published in the following Dove Press journal:

Adolescent Health, Medicine and Therapeutics

29 December 201I

Number of times this article has been viewed

\section{Rebecca S Siegel}

Daniel P Dickstein

Pediatric Mood, Imaging, and NeuroDevelopment Program, EP Bradley Hospital, East Providence, RI, USA
Correspondence: Daniel P Dickstein Pediatric Mood, Imaging, and NeuroDevelopment Program, EP Bradley Hospital, I0II Veterans Memorial Parkway, East Providence, RI 02915, USA

$\mathrm{Tel}+\mathrm{I} 40 \mid 4321616$

Fax + I 40I 432 I607

Email daniel_dickstein@brown.edu
Abstract: Anxiety disorders are the most prevalent mental health concern facing adolescents today, yet they are largely undertreated. This is especially concerning given that there are fairly good data to support an evidence-based approach to the diagnosis and treatment of anxiety, and also that untreated, these problems can continue into adulthood, growing in severity. Thus, knowing how to recognize and respond to anxiety in adolescents is of the utmost importance in primary care settings. To that end, this article provides an up-to-date review of the diagnosis and treatment of anxiety disorders geared towards professionals in primary care settings. Topics covered include subtypes, clinical presentation, the etiology and biology, effective screening instruments, evidence-based treatments (both medication and therapy), and the long-term prognosis for adolescents with anxiety. Importantly, we focus on the most common types of anxiety disorders, often known as phobias, which include generalized anxiety disorder, social anxiety/social phobia, separation anxiety disorder, panic disorder, and specific phobias. In summary, anxiety is a common psychiatric problem for adolescents, but armed with the right tools, primary care providers can make a major impact.

Keywords: anxiety disorders, adolescents, presentation, etiology, assessment, treatment, primary care

\section{Introduction}

Anxiety disorders are among the most important health issues facing adolescents, and also their parents and those who work with and treat adolescents. Yet, there is a bit of a paradox surrounding anxiety disorders in adolescents. On the one hand, we know a great deal about anxiety disorders, including the fact that they are the most common psychiatric disorders among adolescents, with an estimated prevalence of $31 \% .{ }^{1}$ On the other hand, anxiety disorders are the most undertreated mental health problems in adolescents, with recent data indicating that only $18 \%$ of anxious adolescents were in treatment. ${ }^{2}$

How does this make sense? While likely multifactorial, one issue is that there are fewer routine health visits for adolescents than for children, thus providing fewer opportunities for practitioners to pick up on mental health concerns. Also, primary care providers may not have access to the latest research about anxiety disorders in adolescents, given their busy patient loads. Thus, our goal in this paper is to provide a succinct review of what is known about the phenomenology and treatment of anxiety disorders in adolescents.

We will address the following questions: What types of anxiety disorders affect adolescents? How do anxiety disorders present in adolescence? What do we know 
about the etiology and biology underlying anxiety disorders? How can clinicians effectively screen adolescents for anxiety disorders? What evidence-based treatments exist for anxiety disorders in adolescence? What is the long-term prognosis of anxiety disorders in adolescence?

This is no small task, with more than ten distinct types of anxiety disorders currently recognized by the Diagnostic and Statistical Manual, 4th edition, Text Revision (DSM-IV-TR). ${ }^{3}$ Therefore, we will focus on the most common type of anxiety disorders, often referred to as the "phobias". Phobias include several disorders, ie, generalized anxiety disorder, social anxiety/social phobia, separation anxiety disorder, panic disorder, and specific phobias. This approach is also consistent with the growing emphasis, including in the upcoming DSM-V, on shared dimensions of psychiatric disorders, rather than the prior focus on distinct categories. We will not focus on either obsessive compulsive-disorder or posttraumatic stress disorder, because research indicates that these two disorders have biological underpinnings distinct from the phobias. $^{4}$

\section{What types of anxiety disorder affect adolescents? DSM-IV-TR classification}

At their most basic level, all anxiety disorders share common features, including excessive fear, avoidance of whatever is feared, and anticipation and worry when expected to encounter whatever is feared (see Table 1, DSM-IV-TR criteria for different forms of phobia-type anxiety disorders). As mentioned, the anxiety disorders that are covered in this review include generalized anxiety disorder (sustained [for months] of uncontrollable worry about many issues), social phobia (fear of social or performance situations), separation anxiety (worry about separation from home or attachment figures), panic disorder (intense bursts of anxiety that have a sudden start and end [eg, lasting longer than 1 hour] accompanied by physical symptoms such as shortness of breath, palpitations, and dizziness), and specific phobia (fear of a certain object or situation, such as spiders or clowns). In the National Comorbidity Survey-Replication-Adolescent Supplement, an epidemiologic sample of 10,123 adolescents in the US, prevalence estimates for the different anxiety disorders were as follows: generalized anxiety disorder $2.2 \%$, social phobia $9.1 \%$, specific phobia $19.3 \%$, panic disorder $2.3 \%$, and separation anxiety $7.6 \% .{ }^{1}$ Importantly, some DSM-IV-TR anxiety disorders have child-specific modifications for the standard (adult) criteria. For example, child-specific modifications for generalized anxiety disorder include requiring only one associated symptom instead of three for adults, not requiring children to recognize that fears are excessive and unreasonable, and specifying that children may express anxiety behaviorally as crying, tantrums, freezing, or clinging rather than just verbally stating one's fear.

\section{Proposed revisions for the DSM-V}

As this paper is being prepared, the latest revision of DSM is due for publication in 2013. There are a number of proposed revisions, including some affecting anxiety disorders (see www.dsm5.org). For example, in DSM-IV, panic disorder has two different subtypes, ie, panic disorder with agoraphobia (fear of being in a situation where escape might be difficult, such as away from home, in a crowd, in a bus, plane, or train, in the event of a panic attack) and panic disorder without agoraphobia. In the proposed revisions for the DSM-V, panic disorder and agoraphobia are different disorders, rather than agoraphobia being a specifier within the panic disorder diagnosis. In specific phobia and social phobia, one of the proposed changes eliminates the requirement for the individual to recognize that the fear is excessive or unreasonable. Additionally, the duration requirement of at least 6 months is now required for adults as well as children for specific and social phobia. Proposed changes for generalized anxiety disorder include lowering the required timeframe from at least 6 months to at least 3 months and only requiring one "criterion $C$ " symptom, rather than three, for adults as well as children.

\section{How does anxiety present in adolescence? Adolescent-specific presentation}

Anxiety disorders often present prior to adulthood, thus the need for those working with children and adolescents to be vigilant. For example, data from the National Comorbidity Survey Replication, a nationally representative epidemiologic study, found that most anxiety disorders have a median age-of-onset of 11 years. ${ }^{5}$ Primary care providers, as well as adolescents' parents, friends, and caregivers, should be aware that anxiety has a unique presentation in children and adolescents. First, anxiety disorders are generally more common in adolescent girls than boys. ${ }^{1}$ Additionally, youth may exhibit more behavioral manifestations of anxiety rather than the cognitive or conscious endorsement by the patient, as is more common in adults. For example, children and adolescents often have physical complaints or somatic symptoms of anxiety (ie, stomach or headaches), rather than recognizing anxiety symptoms as such. ${ }^{6}$ Similarly, behavioral 
Table I Diagnostic and statistical manual of mental disorders, fourth edition criteria by diagnosis

\begin{tabular}{|c|c|}
\hline Disorder & Symptom criteria \\
\hline Generalized anxiety disorder & $\begin{array}{l}\text { Nonspecific, uncontrollable worry occurring with three or more of the following symptoms } \\
\text { (one for children) } \\
\text { Restlessness } \\
\text { Fatigue } \\
\text { Difficulty concentrating } \\
\text { Irritability } \\
\text { Muscle tension } \\
\text { Sleep difficulties }\end{array}$ \\
\hline Social phobia/social anxiety disorder & $\begin{array}{l}\text { Fear of humiliation or embarrassment in a social or performance situation that involves possible } \\
\text { scrutiny by others. Exposure to the feared object/situation causes immediate anxiety reaction. In } \\
\text { children, this may include crying, tantrums, freezing, clinging. } \\
\text { In children, there must be evidence that they are able to have age-appropriate relationships, and the } \\
\text { anxiety must occur with peers, not just adults. }\end{array}$ \\
\hline Separation anxiety & $\begin{array}{l}\text { Anxiety concerning separation from home or from attachment figures. Must exhibit three of the } \\
\text { following symptoms: } \\
\text { Excessive distress when separation occurs or is anticipated } \\
\text { Worry about attachment figures getting hurt } \\
\text { Refusal to go to school or other places because of fear of separation } \\
\text { Reluctance to be alone or without major attachment figures at home or in other settings } \\
\text { Refusal to sleep alone or away from home } \\
\text { Nightmares about separation } \\
\text { Experiencing physical symptoms (such as headaches, stomach aches, nausea, or vomiting) } \\
\text { during separation or anticipated separation }\end{array}$ \\
\hline Panic disorder & $\begin{array}{l}\text { Criteria for a panic attack } \\
\text { Sudden onset of four or more of the following symptoms: } \\
\text { Racing/pounding heartbeat } \\
\text { Sweating } \\
\text { Trembling or shaking } \\
\text { Shortness of breath } \\
\text { Choking feeling } \\
\text { Chest pain } \\
\text { Nausea/stomach ache } \\
\text { Feeling lightheaded } \\
\text { Derealization/depersonalization } \\
\text { Fear of losing control } \\
\text { Fear of dying } \\
\text { Numbness or tingling sensations } \\
\text { Chills or hot flushes } \\
\text { Panic disorder } \\
\text { Recurrent unexpected Panic Attacks followed by concern about having additional attacks, worry } \\
\text { about the implications of the attack, or a significant change in behavior related to the attacks }\end{array}$ \\
\hline Specific phobia & $\begin{array}{l}\text { Fear of a specific object or situation (eg, flying, heights, animals, receiving injections, seeing blood). } \\
\text { Exposure to the feared object/situation causes immediate anxiety reaction. In children, this may } \\
\text { include crying, tantrums, freezing, clinging. } \\
\text { The person must recognize that the fear is excessive (can be absent in children). }\end{array}$ \\
\hline
\end{tabular}

concerns, such as defiant behavior at home and at school, can also accompany anxiety in youth. ${ }^{7}$ School avoidance, typically due to social phobia or generalized anxiety, is a particularly salient form of such oppositional behavior that often accompanies anxiety, specifically in adolescents. ${ }^{6}$ However, it should be noted that school avoidance is not specific to anxiety disorders, and other causes include learning difficulties or peer conflicts. Studies have demonstrated that school difficulties, decline in school performance, and even high school noncompletion, are associated with anxiety in children and adolescents by some ${ }^{8,9}$ but not all ${ }^{10}$ studies. Social withdrawal from both peers and activities is also common. ${ }^{6}$

Another common feature of the presentation of anxiety disorders is having more than one co-occurring anxiety disorder simultaneously, such as having generalized anxiety disorder and social phobia. This phenomenon, known as "comorbidity", is common in adolescents and adults suffering 
from anxiety disorders. Anxiety and depression are also often comorbid among adolescents. ${ }^{11}$ Data regarding comorbid substance use/abuse is mixed, with some showing anxious adolescents are at reduced risk, ${ }^{12}$ while others have shown increased risk. ${ }^{13,14}$ This may be due to gender differences, with specific types of anxiety disorders, or the interaction. Supporting this possibility, Wu et $\mathrm{al}^{15}$ found alcohol use to be associated with anxiety in adolescent girls but not boys, and also found that agoraphobia, separation anxiety, and obsessive-compulsive disorder were positively associated with illicit drug use in adolescent girls, while separation anxiety was associated with less drug use in the same sample. Learning disabilities ${ }^{16}$ and attention deficit hyperactivity disorder ${ }^{17}$ also commonly co-occur with anxiety disorders in youth.

\section{Normative fears and risk factors}

An important consideration for primary care providers and parents is how to distinguish fears that are part of typical development from an anxiety disorder. Typically during development, children may be afraid of certain objects or situations. For example, it is common for infants and toddlers to be apprehensive of strangers at 12-18 months of age, known as stranger anxiety, or for school-aged children to be somewhat afraid of germs at 5-7 years, or for adolescents to be somewhat concerned about peer acceptance or rejection. ${ }^{18}$ However, these normative fears are typically transient and do not result in functional impairment, in contrast with anxiety disorders which persist and interfere with an adolescent's functioning at home, school, or with peers.

There are several other psychological and environmental risk factors that may differentiate normal fears from anxiety disorders in adolescence. Behavioral inhibition is a temperamental characteristic referring to the trait of some young children to exhibit increased fear in response to new situations. Behavioral inhibition can be assessed via parent-report or retrospective self-report or measured in the laboratory by exposing young children to novel situations and observing their behavior. ${ }^{19}$ Behavioral inhibition is associated with anxiety disorders in later childhood and adolescence. ${ }^{19-21}$ Another risk factor for adolescent anxiety disorders is parental anxiety disorders. Specifically, children and adolescents whose parents have an anxiety disorder are more likely to also exhibit anxiety (eg, odds ratio 4.7 for social phobia), ${ }^{22}$ implicating both genetics and family environment. ${ }^{23} \mathrm{~A}$ third factor that may predispose to anxiety disorders is difficulty with peer relationships, which has been associated with subsequent anxiety, particularly social anxiety, in adolescents. ${ }^{24}$

\section{What do we know about the biology underlying anxiety?}

We know a tremendous amount about the biology of anxiety disorders. This work draws on a translational approach, including animal models, studies of typically developing humans from childhood to adulthood, and research involving patients with anxiety disorders. Moreover, thanks to the field of affective neuroscience, ie, the field of research devoted to the understanding of brain and behavioral underpinnings of psychiatric disorders, this work has ever increasing clinical implications.

Taken as a whole, these studies have demonstrated a "fear circuit" in the brain, comprised of the amygdala, medial and lateral prefrontal cortex, and hippocampus. ${ }^{25}$ Structural magnetic resonance imaging studies have examined changes in gray matter volume associated with anxiety disorders in children. Thus far, these studies are limited in number and mixed in results. Specifically, of two studies examining differences in gray matter in child and adolescent patients with anxiety disorders, both have found amygdala abnormalities. However, while one study found increased amygdala volume in children and adolescents with generalized anxiety disorder as compared with healthy control participants, ${ }^{4,26}$ another found decreased amygdala volume in generalized anxiety disorder versus healthy control youth. ${ }^{26}$

Functional magnetic resonance imaging has also been used to study brain function in anxious youths, as brain activation is measured while participants are completing specific cognitive or emotional tasks. Given the role of the amygdala in both fear circuit and face processing, several studies have examined the role of face processing in child and adolescent anxiety disorders. Studies have found that youth with anxiety disorders have an exaggerated amygdala reaction to viewing fearful faces. For example, Thomas et $\mathrm{al}^{27}$ found that anxious children demonstrated greater amygdala activation in response to fearful faces versus neutral faces as compared with healthy controls and depressed children. Similarly, McClure et $\mathrm{a}^{28}$ found that adolescents with generalized anxiety disorder exhibited a greater difference in amygdala reaction when viewing a fearful versus a happy face as compared with healthy control adolescents. The study also found similar results for prefrontal cortex activation. ${ }^{28}$ Finally, Beesdo et $\mathrm{al}^{18}$ found that, when passively viewing fearful faces, youth with anxiety disorders exhibited a greater amygdala response than depressed and healthy control youth. Taken as a whole, face processing studies 
indicate an exaggerated amygdala response when viewing fearful faces in anxious youth, implicating the amygdala in the etiology of anxiety in children and adolescents.

Functional magnetic resonance imaging has also been used to study the brain response to threatening situations. Many hypothesize that anxious patients have both increased attention to threatening stimuli, and misperceive neutral stimuli as threatening, both of which are modulated by the amygdala and prefrontal cortex. ${ }^{25}$ Several studies have used functional magnetic resonance imaging to examine neural function during threat paradigms in anxious youth. Guyer et $\mathrm{al}^{29}$ used a task in which adolescents were anticipating a negative social evaluation, which is a particularly threatening situation for this age group. They found that anxious adolescents demonstrated greater amygdala activation during the task than healthy control adolescents, and also demonstrated greater connectivity between the amygdala and ventrolateral prefrontal cortex when anticipating the negative social evaluations. ${ }^{29}$ Face processing paradigms can also be used to measure attention to threat using angry faces. Monk et $\mathrm{al}^{30}$ examined adolescents' behavioral and neural responses to angry faces. They found that adolescents with generalized anxiety disorder exhibited a bias away from angry faces, indicating that they avoided the threatening stimulus, as compared with healthy control adolescents. Adolescents with generalized anxiety disorder also showed greater amygdala activation when looking at angry faces as compared with healthy control adolescents.

In summary, structural and functional magnetic resonance imaging studies implicate amygdala alterations in the pathophysiology of anxiety among adolescents. This includes functional magnetic resonance imaging data showing amygdala overactivity when anxious adolescents are engaged in a task that elicits attention to internal feelings of fear, ${ }^{18,28}$ when viewing masked angry faces,${ }^{29}$ and when anticipating a negative social evaluation. ${ }^{31}$ Although more mixed, structural magnetic resonance imaging studies also implicate abnormal amygdala volume among anxious youths, as well as alterations in the prefrontal cortex. ${ }^{28-30}$ When evaluating functional magnetic resonance imaging studies, it is important to keep in mind that some findings may be contradictory, and that functional magnetic resonance imaging cannot be used reliably to diagnose anxiety or any other psychiatric disorders.

\section{How can clinicians effectively screen adolescents for anxiety disorders?}

Screening teens for anxiety disorders in primary care settings is very important, given the high prevalence of anxiety disorders among youth, ${ }^{1}$ but is very difficult, given that contact between primary care providers and adolescents is all too infrequent and brief. In general, there are many different tools to evaluate adolescents for anxiety disorders and other forms of psychiatric problems, including detailed interviews administered by skilled clinicians (physicians, psychologists, social workers, or nurses), patient self-report measures, and parent/teacher report measures. We have listed a variety of these instruments in Table 2 , but primary care providers are most likely to use questionnaires, including patient self-report measures and parent/teacher reports. Primary care providers should use these tools if concerns about potential anxiety arise during an office visit, either through self-reported anxiety symptoms, behavioral concerns that are consistent with anxiety (eg, school refusal, peer difficulties, somatic symptoms), or parent-reported concerns. As recommended by The American Academy of Child and Adolescent Psychiatry in their 2007 practice parameters, ${ }^{32}$ an anxiety assessment should begin with screening questions, such as self-report and parent-report questionnaires, which should then be followed up with a formal evaluation, such as a structured or semistructured interview, if a high level of symptoms are endorsed on the screening measures. It is also important when assessing for anxiety disorders to consider a differential diagnosis of both physical (eg, hyperthyroidism, migraines) and psychiatric (eg, attention deficit hyperactivity disorder, psychotic disorders, learning disability) conditions that may share symptoms of anxiety disorders.

Self-report measures can be used to screen for anxiety or other psychiatric disorders. They require adolescents to rate statements according to how much they apply to themselves using a Likert scale (eg, never, sometimes, often). The advantage of such self-reports is that they are reliable, with standardized scoring including cutoffs to differentiate between normal and abnormal, but they do not require extensive time, either for personnel training or for administration. Self-report measures can be used in the primary care setting if an anxiety disorder is suspected, by giving an adolescent the questionnaire in the waiting room or during their appointment. Primary care providers can then quickly score the measure to determine whether the adolescent meets the clinical cutoff score, indicating that they are at risk for an anxiety disorder.

There are many self-report screening measures for anxiety disorders in youth (see Table 2). Two of the most common self-report measures to screen for anxiety disorders include the Revised Children's Manifest Anxiety 


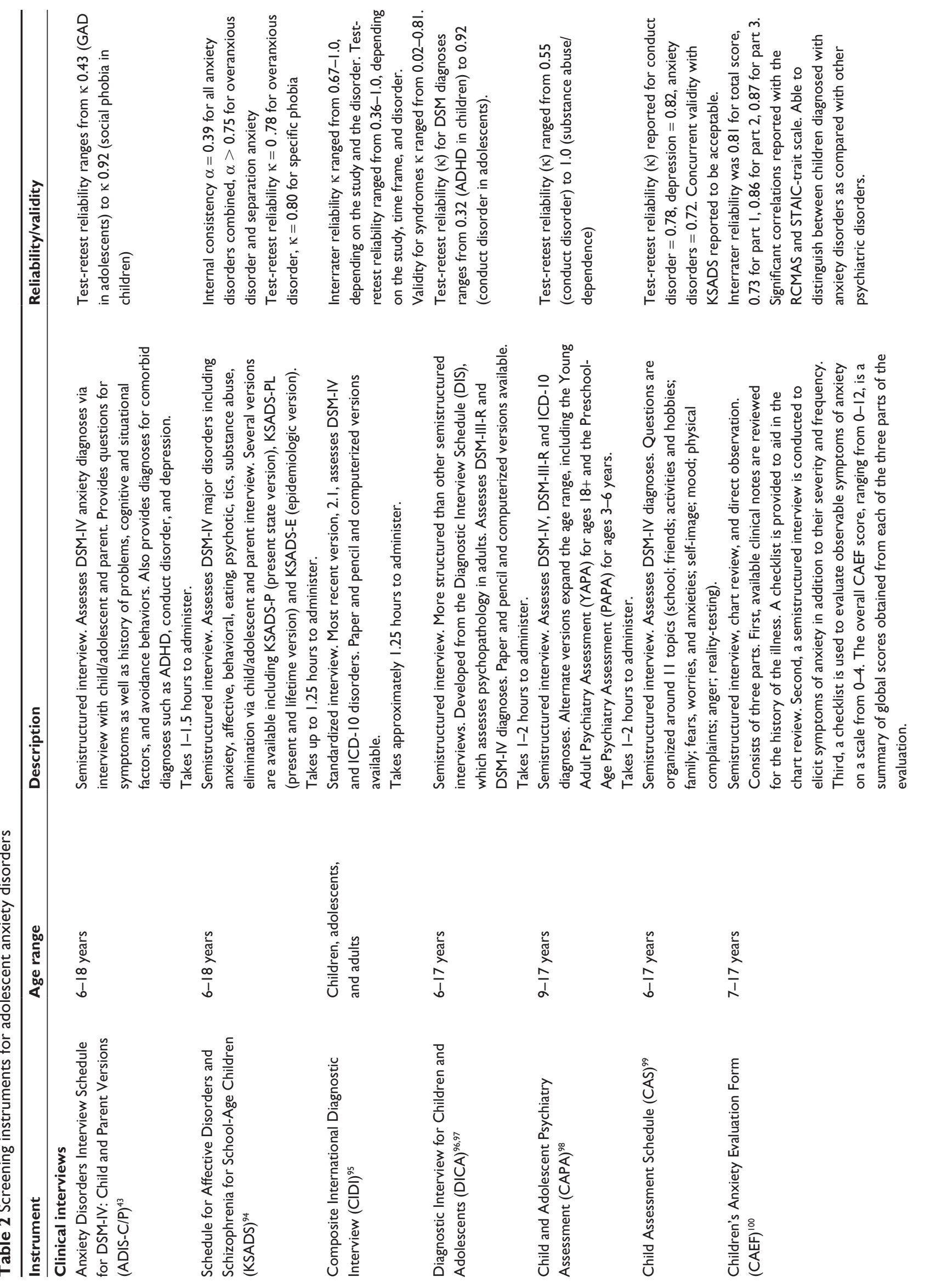



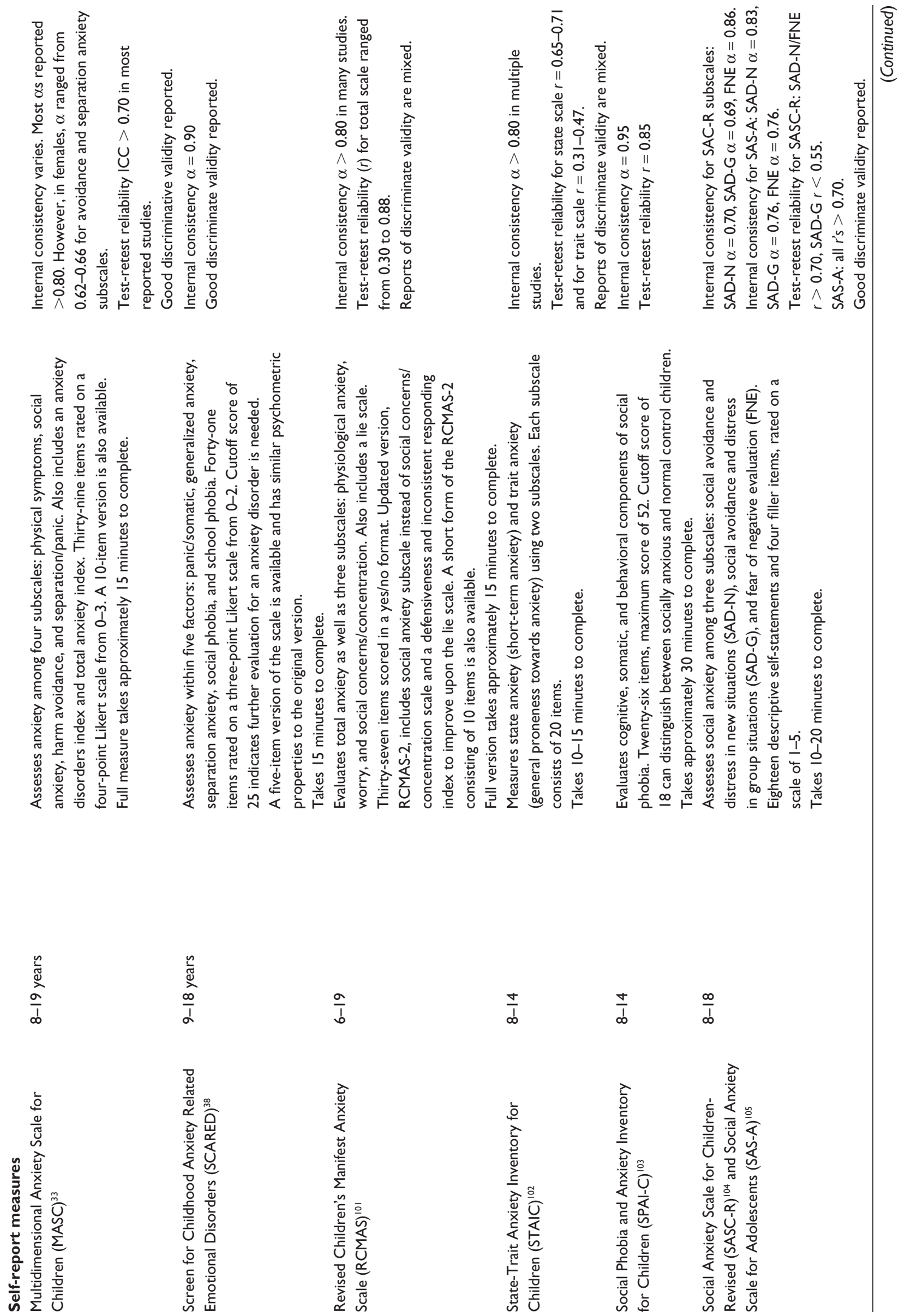


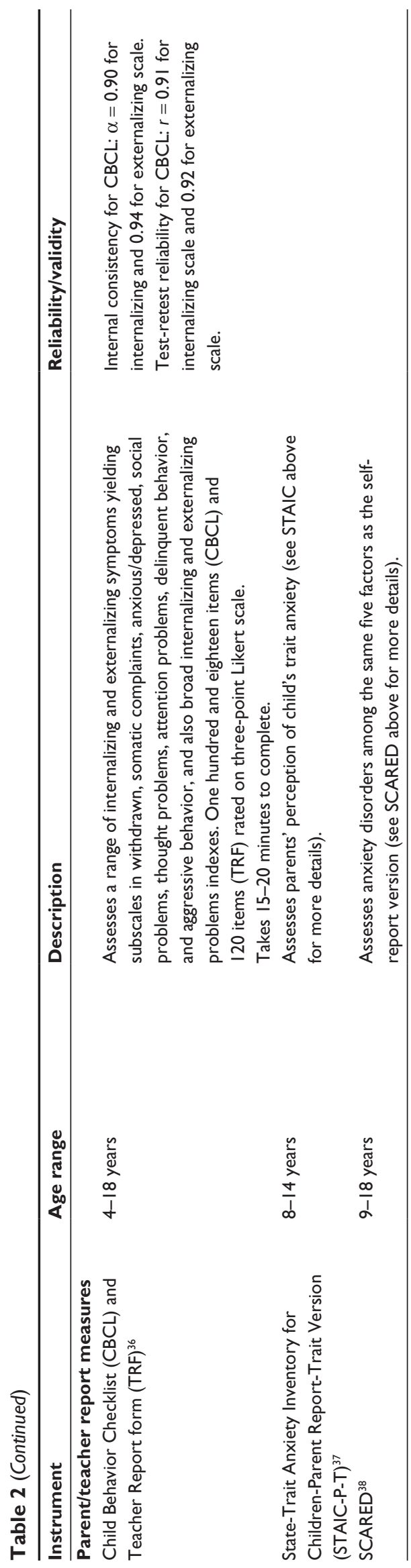

Scale (RCMAS) and the Multidimensional Anxiety Scale for Children (MASC). ${ }^{33,34}$ The most recent version of the RCMAS, ie, RCMAS-2, is comprised of three subscales that measure anxiety, including physiological anxiety, worry, and social anxiety. Two additional indices, the defensiveness subscale and inconsistency index, identify random or untruthful responses. Finally, the total anxiety index indicates youth who are at risk for having an anxiety disorder. The RCMAS has been found to be effective in screening for anxiety disorders in primary care settings. ${ }^{35}$

The MASC was developed specifically for childhood anxiety disorders, rather than being adapted from an adult scale. ${ }^{33}$ The MASC has four subscales, including physical symptoms, harm avoidance, social anxiety, and separation/ panic. The physical symptoms subscale yields further subdivision into somatic symptoms and tense symptoms, the harm avoidance subscale into perfectionism and anxious coping, and the social anxiety subscale into humiliation fears and performance fears. The scale also has an inconsistency index which allows clinicians to identify random or careless responses, and an anxiety index which identifies youth who are at elevated risk for having an anxiety disorder and warrant further evaluation. While a very useful measure commonly used by mental health providers to screen for anxiety disorders, no known studies have explicitly examined the efficacy of the MASC in primary care settings. Due to their extensive use and research base, we recommend using the RCMAS or the MASC for self-report measures of anxiety.

In parallel with adolescent self-report measures, primary care providers may want to use parent and/or teacher report measures which round out the picture. The most widely used general parent/teacher report measure is the Child Behavior Checklist and Teacher Report Form. ${ }^{36}$ The Child Behavior Checklist is not specific to anxiety disorders, and in contrast, provides information about several domains, ie, anxious/ depressed, withdrawn/depressed, somatic complaints, social problems, thought problems (eg, self-harm, sexual preoccupation, auditory hallucinations), attention problems, rulebreaking behavior, and aggressive behavior (see Table 2).

In contrast, anxiety-specific parent measures include parent versions of the State-Trait Anxiety Inventory for Children $^{37}$ and the Screen for Childhood Anxiety Related Emotional Disorders (SCARED).$^{38}$ The social phobia subscale of the parent-report version of the SCARED has been found to be an effective screener for social phobia in a primary care setting. ${ }^{39}$ The SCARED has also been found to have moderate to high correlation between parent-report and child/adolescent-report in primary care. ${ }^{40}$ In general, when 
assessing for anxiety disorders in adolescents, information from multiple informants including youth, parents, and teachers should be gathered whenever possible. ${ }^{41}$ Research has found variable agreement between informants when reporting on mental health symptoms in youth. ${ }^{42}$ Adolescents are typically more aware of their own internal distress, such as their subjective feelings of anxiety, while parents and teachers may have a better sense of how anxiety is disrupting their academic and social functioning. ${ }^{32}$ Teacher-report and parent-report forms can be sent home after an appointment and returned via mail or at the adolescent's next primary care appointment, thus providing more information for the practitioner to use when considering an anxiety diagnosis.

Clinical interviews are the gold standard for diagnostic assessment of anxiety and other psychiatric disorders in children or adults. However, it is unlikely that primary care providers will use these instruments for anxiety or other disorders due to the time and training required to administer them. However, there are several reasons for primary care providers to be aware of these instruments, including the fact that they may see mental health consultants refer to them in their reports.

Clinical interviews can take the form of unstructured, semistructured, and standardized. Unstructured interviews are often used in primary care and mental health settings, and are less reliable because they do not provide a standard set of questions. Semistructured interviews, such as the Anxiety Disorders Interview Schedule for DSM-IV: Child and Parent Version (see Table 2) provide initial screening questions about each disorder of interest (eg, anxiety disorders), with interviewers using follow-up questions for greater detail if a patient/parent endorses those initial screening questions. These instruments are "semistructured" (rather than "structured") because they provide structured questions and prompts for evaluating psychiatric symptoms while allowing for some flexibility and clinical judgment, eg, in which prompts are used. Semistructured interviews are more advantageous than unstructured clinical interviews because clinicians can be trained to be reliable, meaning that they will arrive at the same diagnoses as other trained clinicians when interviewing the same patient. However, training is required to achieve reliability, because untrained individuals must rate standardized videotapes of others' interviews or have trained individuals observe untrained individuals' interviews. Moreover, semistructured interviews often require substantial time to administer. Standardized clinical interviews, such as the Composite International Diagnostic Interview (see Table 2), are more structured than semistructured interviews, because the same set of questions is asked regardless of the interviewee's response. There is little clinical judgment required when administering standardized interviews, and reliability is typically very good. Although less training is required to administer standardized interviews, they are also time-consuming and may not be practical for the primary care setting. Thus, standardized and semistructured interviews may offer the best diagnostic precision in the diagnosis, but are likely inappropriate for the primary care setting due to the time required for training and administration. In terms of structured and semistructured interviews, the Anxiety Disorders Interview Schedule for DSM-IV: Child and Parent Version is the most anxiety-focused measure and, therefore, is recommended. ${ }^{43,44}$

\section{What evidence-based treatments exist for anxiety disorders in adolescence? Psychological treatment}

All too often, psychotherapy is a black box that is not transparent to primary care providers. Thus, we would like to provide a brief description of the major forms of psychotherapy for anxiety disorders including psychoeducation, relaxation techniques, exposures and systematic desensitization, and cognitive behavior therapy. Our goal is to provide an overview of these therapies so as to allow better collaboration with mental health providers, rather than to provide an extensive review or training on all such treatments.

Psychoeducation teaches patients and their parents about anxiety. It can include information about how common or what types of anxiety exist, causes of anxiety disorders (eg, brain changes, genes, environment, and their interaction), physical manifestations of anxiety (eg, racing heart, sweaty palms, headaches, and stomach aches), identification of triggering situations that may lead to anxiety, and the concept that avoiding feared situations can maintain/continue or worsen anxiety. ${ }^{45}$ Primary care providers can administer psychoeducation, as they would for any other illness. Although often paired with other components of therapy (described below), psychoeducation is an important aspect of therapy for anxiety disorders of all types and levels of severity.

Relaxation techniques can also be used in a primary care setting. The technique involves teaching relaxation strategies, such as deep breathing, progressive muscle relaxation, and guided imagery that adolescents can then practice at home. For deep breathing, the adolescent is instructed to take a deep breath in through the nose and out through the 
mouth while feeling his or her stomach rise and fall with the breath. Progressive muscle relaxation involves tensing and then relaxing muscle groups one at a time throughout the body (eg, tense and relax toes, ankles, and calves). Guided imagery instructs adolescents to picture a relaxing setting while practicing deep breathing. Therapists teach adolescents to generate the relaxation response, ie, that feeling of relaxation and well-being, during their office-based sessions, that can then be practiced and generalized to other settings where anxiety is more common, such as at school or with peers. Although often paired with other techniques, research has shown that relaxation techniques alone can be effective in significantly reducing anxiety symptoms in adolescents. ${ }^{46}$ Applied relaxation is a technique that has been shown to be effective, particularly for adults with generalized anxiety disorder, in which anxious patients first learn relaxation techniques, such as progressive muscle relaxation, and then learn to apply these techniques during anxiety-provoking situations when they arise in order to control the somatic anxiety response..$^{47}$ Relaxation techniques are particularly effective for those who experience a strong somatic component to their anxiety. However, some experts theorize that relaxation techniques reinforce avoidance behavior and may perpetuate anxiety symptoms in the long term.

Exposure tasks are more complex to conduct and are best utilized in a mental health setting rather than in primary care. During exposure tasks, patients are encouraged to expose themselves to feared situations or stimuli (eg, speaking in public, spiders) in order to reduce avoidance of these situations/stimuli. The goal of exposure is to allow the adolescent to "habituate" to the feared situations/stimuli, meaning they learn that anxiety symptoms will eventually subside on their own without any harmful effects. This leads to extinction, in which the feared situation/stimulus no longer provokes the anxious response. Exposure can be conducted using a fear hierarchy, in which the therapy begins with situations/stimuli that are the least feared and builds up to those that produce the greatest anxiety symptoms. ${ }^{48}$ Exposure tasks are also typically combined with other techniques in therapy, although some research has found that in vivo exposures (eg, touching a spider for a spider phobia) may be effective for specific phobias in as few as $1-2$ sessions. ${ }^{49,50}$ Systematic desensitization is a related technique, in which patients are exposed to anxiety-provoking situations, either in vivo or imaginal (ie, they imagine the anxiety-provoking stimulus) and practice using relaxation techniques during the exposure. ${ }^{51}$ Exposure techniques can be very effective for a wide variety of anxiety symptoms and severity levels.
Cognitive behavioral therapy is a form of psychotherapy for anxiety that combines some of the abovementioned techniques with additional treatment components. Cognitive behavior therapy is best used in the context of a longer-term treatment in a mental health setting. At its core, cognitive behavior therapy is based on the idea that one's thoughts (cognitions), feelings (emotions), and behavior interact, with the goal of cognitive behavior therapy being to identify and to change cognitions and behavior that are maintaining the disorder, thus reducing symptoms and improving a patient's ability to function..$^{52}$ For example, an adolescent with social phobia might be preoccupied with thoughts about being ridiculed by their peers at an upcoming social event. In terms of behavior, avoiding the feared situation or stimulus, such as not going to the social event in the previous example, often maintains and worsens the anxiety symptoms. In terms of emotions, the feelings of anxiety and possibly poor selfesteem or depression would result from such cognitions and behavior, according to the cognitive behavior therapy model. Cognitive behavior therapy is often disorder-specific, meaning tailored to address particular types of cognitions, emotions, and behaviors associated with one illness, ie, anxiety or depression. The therapy for anxiety disorders typically consists of several techniques, including psychoeducation and exposure tasks, as mentioned above, in addition to cognitive restructuring. Cognitive restructuring teaches patients new, more adaptive ways of thinking, such as realizing that they cannot control others' behavior or know what others are thinking. For example, for the socially phobic adolescent described above, cognitive restructuring might help the adolescent think of times when they attended a social event and were not ridiculed, or realize that they cannot read the minds of peers to know if they are judging them.

Cognitive behavior therapy has the best evidence-base for treatment of anxiety disorders. This therapy was first used with adults but significant research has now shown that it is also effective for children and adolescents. Individual and group cognitive behavior therapy protocols have both been used effectively to treat anxiety disorders in youth. ${ }^{53}$ In the first randomized, controlled trial of individual cognitive behavior therapy for anxiety disorders in youth, Kendall ${ }^{54}$ used the "Coping Cat" program to treat 27 youth aged 9-13 years with anxiety disorders compared with 20 youth in a wait-list control condition. The "Coping Cat" program focuses on recognizing and reducing somatic symptoms that accompany anxiety, identifying and coping with maladaptive cognitions present in anxiety-provoking situations, and evaluating performance and providing reinforcement. 
A workbook format is used in which a cartoon cat guides children through the different components of the treatment. After treatment, participants who received cognitive behavior therapy were significantly less anxious on many self-report and parent-report measures of anxiety as compared with wait-list control participants. ${ }^{54}$ The "Coping Cat" program can be used with adolescents, ${ }^{55}$ and a manualized adaptation of the program for adolescents, called the CAT project, has also been created. ${ }^{56}$ Some other individualized cognitive behavior therapy protocols have also been shown to be effective in treating youth with anxiety disorders. ${ }^{34,57-59}$ However, many of these studies have examined primarily children and younger adolescents.

Cognitive behavior therapy is not just for individual therapy, because group cognitive behavior therapy has also been effective in treating anxiety disorders in adolescents. Treating anxiety disorders in a group format for adolescents seems logical, given the importance of peers and social interactions in the normal development of adolescents. Moreover, group cognitive behavior therapy provides the opportunity for peer modeling, social interactions, and exposure to potentially feared interpersonal situations. ${ }^{60}$ This is particularly true with social phobia, for which several group treatments have been developed and proven effective in adolescents. ${ }^{61,62}$ Although fewer group treatments are available for other types of anxiety disorders in adolescents, Hudson et $\mathrm{al}^{63}$ found a group treatment with a cognitive behavior therapy component to be more effective than noncognitive behavioral group therapy in treating youth aged 7-16 years with mixed anxiety diagnoses. Studies comparing group with individual cognitive behavior therapy for anxiety disorders in youth have generally found them to be comparable. ${ }^{60}$

Other psychosocial treatment modalities have also been researched for adolescent anxiety disorders. For example, Social Effectiveness Training for Children (SET-C) is a treatment for children and adolescents with social phobia. ${ }^{64}$ The SET-C program comprises psychoeducation, social skills training, and peer generalization, and exposure tasks. Research has found social skills deficits in youth with social phobia, possibly because adolescents with social phobia avoid peer interactions and fail to acquire age-appropriate social skills. ${ }^{65}$ The social skills training in SET-C includes greetings and introductions, starting conversations, maintaining conversations, listening and remembering skills, skills for joining groups, positive assertion, negative assertion, and telephone skills. ${ }^{66}$ This social skills training may be different from social skills training for other disorders, such as autism spectrum disorders, because treatments for autism spectrum disorders may include the abovementioned skills but also focus on the difficulties with perspective-taking and reading social cues that often accompany autism spectrum disorders, which is not typically seen in adolescents with social phobia. ${ }^{66}$ Peer generalization for this program involves practicing newly acquired social skills with nonanxious peers in an informal setting. SET-C was originally shown to be successful with children aged $8-12$ years ${ }^{64}$ and was also used effectively with adolescents..$^{62,67}$ There are some selfhelp guides for parents or adolescents, that may be helpful tools to recommend to patients for use in conjunction with other forms of treatment. ${ }^{68}$

Supportive therapy is another type of treatment in which the therapist listens to the patient's concerns and provides empathy and support through techniques such as active and reflective listening. This type of therapy, combined with a psychoeducational component, has been used as a comparison treatment in cognitive behavior therapy studies, and has not been found to be effective to treat anxiety disorders. ${ }^{34,69}$

\section{Pharmacological treatment}

In general, the main category of medications that have been studied for the treatment of anxiety disorders in children and adolescents are the selective serotonin reuptake inhibitors. Randomized, placebo-controlled trials have found fluoxetine,${ }^{70}$ fluvoxamine, ${ }^{71}$ paroxetine, ${ }^{72}$ and sertraline ${ }^{59}$ to be superior to placebo in reducing the severity of anxiety for youth with generalized anxiety disorder, social phobia, and separation anxiety disorder. In perhaps one of the largest randomized, controlled trials in anxious youth, Walkup et al from the Child/Adolescent Anxiety Multimodal Study of 488 children aged 7-17 years found that the combination of sertraline plus cognitive behavioral therapy was more effective than either treatment alone or placebo in reducing severity of anxiety. ${ }^{59}$ Other selective serotonin reuptake inhibitors, including escitalopram ${ }^{73}$ and citalopram ${ }^{74}$ have also proven effective in open trials for reducing anxiety symptoms in youth.

Although the selective serotonin reuptake inhibitors have become the first-line among medication treatments for anxiety disorders in children, safety considerations are important. This is especially true following the US Food and Drug Administration issuing of a black box warning on these medications that focuses on potential for suicidality in October 2004. This black box warning now extends to all patients aged 25 years or younger (http://www.fda.gov/Drugs/DrugSafety/InformationbyDrugClass/UCM096273). ${ }^{75}$ Current guidelines suggest that adequate parental and patient consent 
should be obtained from any patient potentially being prescribed serotonergic antidepressants. This should include a discussion of risks, benefits, and alternatives. Close monitoring is indicated, especially during the first 3 months of initiating these agents or during times of dose changes. Some suggest this monitoring should include weekly contact with the prescriber during the first 8 weeks, although not all of this need be face to face. Primary care providers should also consult either the American Academy of Pediatrics (www. aap.org) or American Academy of Child and Adolescent Psychiatry (www.aaca.org) for the latest information about this evolving topic.

These medications are generally well tolerated, especially when following the typical prescribing advice for children of "start low, go slow". Common side effects include abdominal pain, nausea, headaches, and drowsiness. ${ }^{70}$ More importantly, since 2003, clinicians and researchers alike have been concerned about suicidality in pediatric populations. Clinicians should educate their patients about this potential risk as well as monitor patients frequently, especially in the first 2-3 months of initiating a selective serotonin reuptake inhibitor.

Primary care providers often wonder which selective serotonin reuptake inhibitor to use first. Following the black box warning, there is more safety evidence for fluoxetine, sertraline, and citalopram. Others suggest that a history of a positive response or side effects in first-degree relatives should guide clinicians, given that the enzymes metabolizing these agents are inherited to some degree. Whichever agent is selected, primary care providers are urged to establish target symptoms by which to measure treatment success or failure in close collaboration with patients and their parents. An adequate trial should be considered of 6-8 weeks at an age-appropriate dose. If no response occurs, then switching to a different selective serotonin reuptake inhibitor for the same duration is often the next step, although care must be taken to wean down the first selective serotonin reuptake inhibitor to avoid excessive serotonin levels and the risk of serotonin syndrome.

In addition to selective serotonin reuptake inhibitors, a serotonin-norepinephrine reuptake inhibitor, venlafaxine, has also been shown to be effective in treating anxiety disorders in youth. In a randomized, placebo-controlled trial in children aged 8-17 years with social phobia, March et al ${ }^{16}$ found venlafaxine extended-release to be associated with significant improvement on the Clinical Global ImpressionImprovement (CGI-I) scale. Similarly, Rynn et $\mathrm{al}^{77}$ found venlafaxine extended-release to be superior to placebo in reducing anxiety symptoms in youth with generalized anxiety disorder as compared with placebo in a randomized, controlled trial. Some mild side effects were noted, including asthenia (bodily weakness), pain (eg, headache, abdominal pain), anorexia, and fatigue. ${ }^{77}$

Sometimes primary care providers wonder about using nonserotonergic agents, such as benzodiazepines. Studies have shown that benzodiazepines can be used successfully to treat anxiety in adults. ${ }^{78,79}$ With respect to randomized, controlled trials in pediatrics, Simeon and Ferguson ${ }^{80}$ demonstrated that alprazolam in youth diagnosed with overanxious and avoidant disorder was no more effective than placebo in reducing severity of anxiety. Moreover, two other concerns about potential side effects may cause clinicians to pause when considering benzodiazepines for anxiety. First and foremost, all patients, ie, children, adolescents, and adults, may potentially become addicted to benzodiazepines, because physiological tolerance (ie, needing greater benzodiazepine doses to achieve the same antianxiety effect) may develop rapidly. Secondly, pediatric patients are especially vulnerable to paradoxical reactions with benzodiazepines, including disinhibition and aggression. Importantly, care should be taken to avoid benzodiazepines with very short half-lives, such as alprazolam or lorazepam, because they are most likely to cause both tolerance and disinhibition. Thus, in general, for anxiety in the pediatric patient, benzodiazepines may be best suited to short-term treatment of phobias, ie, to fly despite fear of flying, or to reduce anxiety associated with eating anxiety in those with eating disorders during initial refeeding. ${ }^{81}$

\section{What is the long-term prognosis of anxiety disorders in adolescence?}

In general, anxiety disorders may be chronic conditions, with adolescents having anxiety disorders continuing to experience difficulties in multiple domains in later adolescence and adulthood. For example, in an epidemiological study of 776 children and adolescents, Pine et $\mathrm{al}^{82}$ found that anxiety disorders in childhood and adolescence were strongly predictive of anxiety in young adulthood. Similarly, Woodward and Fergusson ${ }^{83}$ studied an epidemiological sample of 964 adolescents in New Zealand, and found strong associations between anxiety disorders in adolescence and future anxiety disorders in later adolescence and young adulthood. In another epidemiological of 1228 adolescents in Germany, Wittchen et $\mathrm{al}^{84}$ found that anxiety disorder status was not stable across a 19-month period in adolescence, with approximately $20 \%$ of adolescents who met the full criteria 
for an anxiety disorder at baseline still meeting the criteria for an anxiety disorder at follow-up. However, $42 \%$ of these adolescents were still experiencing anxiety symptoms despite not meeting full criteria for an anxiety disorder. ${ }^{84}$ In a sample of clinically referred children and adolescents, Last et $\mathrm{al}^{85}$ found that approximately $50 \%$ of their sample had recovered from their initial anxiety disorder after 3-4 years of follow-up, but were significantly more likely than healthy control participants to have developed another form of psychopathology, primarily another anxiety disorder. ${ }^{85}$ The study also examined several variables that may predict recovery including age, gender, history of depression, treatment, family history of an anxiety disorder, and illness severity, but none was a significant predictor. However, youth who received treatment were less likely to develop a new anxiety disorder at follow-up. ${ }^{85}$ Thus, although their initial diagnosis may remit, individuals diagnosed with an anxiety disorder in adolescence typically continue to exhibit significant symptoms of anxiety or develop a new anxiety disorder diagnosis throughout adolescence and into adulthood.

In addition to the continuation of anxiety symptoms, adolescents with anxiety disorders are also at risk for developing other forms of psychopathology longitudinally. Research has repeatedly shown that having an anxiety disorder or experiencing significant symptoms of anxiety in adolescence is a risk factor for adult depression. ${ }^{82,83,86-89}$ Anxiety disorders in adolescence also pose an increased risk for suicidal behavior, but only in the presence of comorbid depression. ${ }^{90,91}$ One study found that female gender was a predictor of developing depression in adulthood, but a second study did not find gender to be a predictor. ${ }^{88}$ Some research has also found that anxiety in youth is associated with increased alcohol and drug use longitudinally. ${ }^{83,92,93}$ Having multiple anxiety disorders in adolescence was found in one study to be associated with a greater risk for developing both depression and substance use disorders in adulthood. ${ }^{83}$

\section{Conclusion}

In summary, anxiety disorders in adolescents are an undertreated major health concern. They present similarly to adult anxiety disorders with some additional features, including somatic symptoms, behavioral concerns, and comorbidity. Affective neuroscience has provided a window into the underlying brain mechanisms that might be involved in anxiety disorders, the most significant of which is at the level of the amygdala. In terms of assessment, structured interviews are the most thorough way to diagnose adolescent anxiety disorders, but self-report and parent-report measures, such as the MASC, RCMAS, and Child Behavior Checklist are effective screening measures in a primary care setting. Anxiety disorders can be treated using psychotherapy, most notably cognitive behavioral therapy and pharmacological interventions, and a combination of both of these modalities is the most effective form of treatment. Adolescent anxiety typically follows a chronic course with and also leads to other disorders such as depression and substance use in adulthood.

While much is known about adolescent anxiety disorders, there are still many areas for future research. For example, many psychosocial treatments have been developed for children or adults and then used for adolescents in an adapted form. More research is needed in adolescents independently of children and adults in many areas of adolescent anxiety disorders. Nevertheless, research has made significant strides towards our understanding of adolescent anxiety disorders, and many tools and resources are available to assist clinicians in the understanding, identification, and treatment of these disorders.

\section{Disclosure}

No support was received for this work. Daniel P Dickstein's research is supported currently by R01MH087513, R01MH092450, and R01MH087513 without any industry support present or past. The authors have no other relevant affiliations or financial involvement with any organization or entity with a financial interest in or financial conflict with the subject matter or materials discussed in the manuscript apart from those disclosed.

\section{References}

1. Merikangas KR, He JP, Burstein M, et al. Lifetime prevalence of mental disorders in US adolescents: results from the National Comorbidity Survey Replication -Adolescent Supplement (NCS-A). J Am Acad Child Adolesc Psychiatry. 2010;49:980-989.

2. Merikangas KR, He JP, Burstein M, et al. Service utilization for lifetime mental disorders in U.S. adolescents: results of the National Comorbidity Survey-Adolescent Supplement (NCS-A). J Am Acad Child Adolesc Psychiatry. 2011;50:32-45.

3. American Psychiatric Association. Diagnostic and Statistical Manual of Mental Disorders, 4th ed. Text Revision; 2000.

4. De Bellis MD, Casey BJ, Dahl RE, et al. A pilot study of amygdala volumes in pediatric generalized anxiety disorder. Biol Psychiatry. 2000;48:51-57.

5. Kessler RC, Angermeyer M, Anthony JC, et al. Lifetime prevalence and age-of-onset distributions of mental disorders in the World Health Organization's World Mental Health Survey Initiative. World Psychiatry. 2007;6:168-176.

6. Garland EJ. Rages and refusals. Managing the many faces of adolescent anxiety. Can Fam Physician. 2001;47:1023-1030.

7. Frick PJ, Lilienfeld SO, Ellis M, Loney B, Silverthorn P. The association between anxiety and psychopathy dimensions in children. JAbnorm Child Psychol. 1999;27:383-392. 
8. Duchense S, Vitaro F, Larose S, Tremblay RE. Trajectories of anxiety during elementary-school years and the prediction of high school noncompletion. J Youth Adolesc. 2008;37:1134-1146.

9. Pomerantz EM, Altermatt ER, Saxon JL. Making the grade but feeling distressed: Gender differences in academic performance and internal distress. J Educ Psychol. 2002;94:396-404.

10. Strahan EY. The effects of social anxiety and social skills on academic performance. Pers Individ Dif. 2003;34:347-366.

11. Ollendick TH, Hirshfeld-Becker DR. The developmental psychopathology of social anxiety disorder. Biol Psychiatry. 2002;51:44-58.

12. Malmberg M, Overbeek G, Monshouwer K, Lammers J, Vollebergh WA, Engels RC. Substance use risk profiles and associations with early substance use in adolescence. J Behav Med. 2010;33:474-485.

13. Low NC, Lee SS, Johnson JG, Williams JB, Harris ES. The association between anxiety and alcohol versus cannabis abuse disorders among adolescents in primary care settings. Fam Pract. 2008;25:321-327.

14. Kilgus MD, Pumariega AJ. Psychopathology in cocaine-abusing adolescents. Addict Disord Their Treat. 2009;8:138-144.

15. Wu P, Goodwin RD, Fuller C, Comer JS, Cohen P, Hoven CW. The relationship between anxiety disorders and substance use among adolescents in the community: Specificity and gender differences. J Youth Adolesc. 2010;39:177-188.

16. Nelson JM, Harwood H. Learning disabilities and anxiety: a metaanalysis. J Learn Disabil. 2011;44:3-17.

17. Baldwin JS, Dadds MR. Examining alternative explanations of the covariation of ADHD and anxiety symptoms in children: a community study. J Abnorm Child Psychol. 2008;36:67-79.

18. Beesdo K, Lau JY, Guyer AE, et al. Common and distinct amygdalafunction perturbations in depressed vs anxious adolescents. Arch Gen Psychiatry. 2009;66:275-285.

19. Hirshfeld-Becker DR, Micco J, Henin A, Bloomfield A, Biederman J, Rosenbaum J. Behavioral inhibition. Depress Anxiety. 2008;25: 357-367.

20. Hirshfeld-Becker DR, Biederman J, Henin A, et al. Behavioral inhibition in preschool children at risk is a specific predictor of middle childhood social anxiety: a five-year follow-up. J Dev Behav Pediatr. 2007;28:225-233.

21. Kagan J, Reznick JS, Snidman N, Gibbons J, Johnson MO. Childhood derivatives of inhibition and lack of inhibition to the unfamiliar. Child Dev. 1988;59:1580-1589.

22. Lieb R, Wittchen HU, Hofler M, Fuetsch M, Stein MB, Merikangas KR. Parental psychopathology, parenting styles, and the risk of social phobia in offspring: a prospective-longitudinal community study. Arch Gen Psychiatry. 2000;57:859-866.

23. Merikangas KR, Avenevoli S, Dierker L, Grillon C. Vulnerability factors among children at risk for anxiety disorders. Biol Psychiatry. 1999;46:1523-1535.

24. Siegel RS, La Greca AM, Harrison HM. Peer victimization and social anxiety in adolescents: prospective and reciprocal relationships. JYouth Adolesc. 2009;38:1096-1109.

25. Pine DS. Integrating research on development and fear learning: a vision for clinical neuroscience? Depress Anxiety. 2009;26:775-779.

26. Milham MP, Nugent AC, Drevets WC, et al. Selective reduction in amygdala volume in pediatric anxiety disorders: a voxel-based morphometry investigation. Biol Psychiatry. 2005;57:961-966.

27. Thomas KM, Drevets WC, Whalen PJ, et al. Amygdala response to facial expressions in children and adults. Biol Psychiatry. 2001;49: 309-316.

28. McClure EB, Monk CS, Nelson EE, et al. Abnormal attention modulation of fear circuit function in pediatric generalized anxiety disorder. Arch Gen Psychiatry. 2007;64:97-106.

29. Guyer AE, Lau JY, McClure-Tone EB, et al. Amygdala and ventrolateral prefrontal cortex function during anticipated peer evaluation in pediatric social anxiety. Arch Gen Psychiatry. 2008;65:1303-1312.

30. Monk CS, Nelson EE, McClure EB, et al. Ventrolateral prefrontal cortex activation and attentional bias in response to angry faces in adolescents with generalized anxiety disorder. Am J Psychiatry. 2006;163: 1091-1097.
31. Monk CS, Telzer EH, Mogg K, et al. Amygdala and ventrolateral prefrontal cortex activation to masked angry faces in children and adolescents with generalized anxiety disorder. Arch Gen Psychiatry. 2008;65:568-576.

32. Connolly SD, Bernstein GA. Practice parameter for the assessment and treatment of children and adolescents with anxiety disorders. J Am Acad Child Adolesc Psychiatry. 2007;46:267-283.

33. March JS, Parker JD, Sullivan K, Stallings P, Conners CK. The Multidimensional Anxiety Scale for Children (MASC): factor structure, reliability, and validity. J Am Acad Child Adolesc Psychiatry. 1997;36:554-565.

34. Silverman WK, Kurtines WM, Ginsburg GS, Weems CF, Lumpkin PW, Carmichael DH. Treating anxiety disorders in children with group cognitive-behaviorial therapy: a randomized clinical trial. J Consult Clin Psychol. 1999;67:995-1003.

35. Merritt KA, Thompson Jr RJ, Keith BR, Gustafson KE, Murphy LB, Johndrow DA. Screening for child-reported behavioral and emotional problems in primary care pediatrics. Percept Mot Skills. 1995;80:323-329.

36. Achenbach TM, Howell CT, Quay HC, Conners CK. National survey of problems and competencies among four- to sixteen-year-olds: parents' reports for normative and clinical samples. Monogr Soc Res Child Dev. $1991 ; 56: 1-131$

37. Southam-Gerow MA, Flannery-Schroeder EC, Kendall PC. A psychometric evaluation of the parent report form of the State-Trait Anxiety Inventory for Children - Trait Version. J Anxiety Disord. 2003;17: 427-446.

38. Birmaher B, Brent DA, Chiappetta L, Bridge J, Monga S, Baugher M. Psychometric properties of the Screen for Child Anxiety Related Emotional Disorders (SCARED): a replication study. J Am Acad Child Adolesc Psychiatry. 1999;38:1230-1236.

39. Bailey KA, Chavira DA, Stein MT, Stein MB. Brief measures to screen for social phobia in primary care pediatrics. J Pediatr Psychol. 2006;31:512-521.

40. Wren FJ, Bridge JA, Birmaher B. Screening for childhood anxiety symptoms in primary care: integrating child and parent reports. J Am Acad Child Adolesc Psychiatry. 2004;43:1364-1371.

41. De Los RA, Kazdin AE. Informant discrepancies in the assessment of childhood psychopathology: a critical review, theoretical framework, and recommendations for further study. Psychol Bull. 2005;131:483-509.

42. Choudhury MS, Pimentel SS, Kendall PC. Childhood anxiety disorders: parent-child (dis)agreement using a structured interview for the DSM-IV. J Am Acad Child Adolesc Psychiatry. 2003;42: 957-964.

43. Silverman WK, Saavedra LM, Pina AA. Test-retest reliability of anxiety symptoms and diagnoses with the Anxiety Disorders Interview Schedule for DSM-IV: child and parent versions. J Am Acad Child Adolesc Psychiatry. 2001;40:937-944.

44. Silverman WK, Ollendick TH. Evidence-based assessment of anxiety and its disorders in children and adolescents. J Clin Child Adolesc Psychol. 2005;34:380-411.

45. Kendall PC, Hedtke K. Cognitive-Behavioral Therapy for Anxious Children: Therapist Manual. Ardmore, PA: Workbook Publishing; 2006.

46. Carlson CR, Hoyle RH. Efficacy of abbreviated progressive muscle relaxation training: a quantitative review of behavioral medicine research. J Consult Clin Psychol. 1993;61:1059-1067.

47. Ost LG. Applied relaxation: description of a coping technique and review of controlled studies. Behav Res Ther. 1987;25: 397-409.

48. Compton SN, Walkup JT, Albano AM, et al. Child/Adolescent Anxiety Multimodal Study (CAMS): rationale, design, and methods. Child Adolesc Psychiatry Ment Health. 2010;4:1.

49. Ost LG, Svensson L, Hellstrom K, Lindwall R. One-Session treatment of specific phobias in youths: a randomized clinical trial. J Consult Clin Psychol. 2001;69:814-824.

50. Muris P, Merckelbach H, Holdrinet I, Sijsenaar M. Treating phobic children: effects of EMDR versus exposure. J Consult Clin Psychol. 1998;66:193-198. 
51. Holoroyd KA. Cognition and Desensitization in the Group Treatment of Test Anxiety. J Consult Clin Psychol. 1976;44:991-1001.

52. Reinecke MA, Dattilio FM, Freeman A. What makes for an effective treatment? In: Reinecke MA, Dattilio FM, Freeman A, editors. Cognitive Therapy with Children and Adolescents: A Casebook for Clinical Practice. 2nd ed. New York: The Guilford Press; 2003:1-18.

53. Silverman WK, Pina AA, Viswesvaran C. Evidence-based psychosocial treatments for phobic and anxiety disorders in children and adolescents. J Clin Child Adolesc Psychol. 2008;37:105-130.

54. Kendall PC. Treating anxiety disorders in children: results of a randomized clinical trial. J Consult Clin Psychol. 1994;62:100-110.

55. Beidas RS, Benjamin CL, Puleo CM, Edmunds JM, Kendall PC. Flexible Applications of the Coping Cat Program for Anxious Youth. Cogn Behav Pract. 2010;17:142-153.

56. Kendall PC, Choudhurry M, Hudson J, Webb A. "The CAT Project." Manual for the Cognitive Behavioral Treatment of Anxious Adolescents. 2002.

57. Barrett PM, Dadds MR, Rapee RM. Family treatment of childhood anxiety: a controlled trial. J Consult Clin Psychol. 1996;64:333-342.

58. Kendall PC, Safford S, Flannery-Schroeder E, Webb A. Child anxiety treatment: outcomes in adolescence and impact on substance use and depression at 7.4-year follow-up. J Consult Clin Psychol. 2004;72:276-287.

59. Walkup JT, Albano AM, Piacentini J, et al. Cognitive behavioral therapy, sertraline, or a combination in childhood anxiety. $N$ Engl $J$ Med. 2008;359:2753-2766.

60. Flannery-Schroeder E, Kendall PC. Group and individual cognitive behavioral treatments for youth with anxiety disorders: A randomized clinical trial. Cognit Ther Res. 2000;24:251-278.

61. Hayward C, Varady S, Albano AM, Thienemann M, Henderson L, Schatzberg AF. Cognitive-behavioral group therapy for social phobia in female adolescents: results of a pilot study. JAm Acad Child Adolesc Psychiatry. 2000;39:721-726.

62. Baer S, Garland EJ. Pilot study of community-based cognitive behavioral group therapy for adolescents with social phobia. J Am Acad Child Adolesc Psychiatry. 2005;44:258-264.

63. Hudson JL, Rapee RM, Deveney C, Schniering CA, Lyneham HJ, Bovopoulos N. Cognitive-behavioral treatment versus an active control for children and adolescents with anxiety disorders: a randomized trial. J Am Acad Child Adolesc Psychiatry. 2009;48:533-544.

64. Beidel DC, Turner SM, Morris TL. Behavioral treatment of childhood social phobia. J Consult Clin Psychol. 2000;68:1072-1080.

65. Beidel DC, Turner SM, Morris TL. Psychopathology of childhood social phobia. JAm Acad Child Adolesc Psychiatry. 1999;38:643-650.

66. White SW, Scahill L, Klin A, Koenig K, Volkmar FR. Educational placements and service use patterns of individuals with autism spectrum disorders. J Autism Dev Disord. 2007;37:1403-1412.

67. Garcia-Lopez LJ, Olivares J, Beidel D, Albano AM, Turner S, Rosa AI. Efficacy of three treatment protocols for adolescents with social anxiety disorder: a 5-year follow-up assessment. J Anxiety Disord. 2006;20:175-191.

68. Foa EB, Andrews LW. If Your Adolescent Has an Anxiety Disorder: An Essential Resource for Parents. New York: Oxford University Press, Inc; 2006.

69. Kendall PC, Hudson JL, Gosch E, Flannery-Schroeder E, Suveg C. Cognitive-behavioral therapy for anxiety disordered youth: a randomized clinical trial evaluating child and family modalities. J Consult Clin Psychol. 2008;76:282-297.

70. Birmaher B, Axelson DA, Monk K, et al. Fluoxetine for the treatment of childhood anxiety disorders. $J$ Am Acad Child Adolesc Psychiatry. 2003;42:415-423.

71. RUPP. Fluvoxamine for the treatment of anxiety disorders in children and adolescents. N Engl J Med. 2001;344:1279-1286.

72. Wagner KD, Berard R, Stein MB, et al. A multicenter, randomized, double-blind, placebo-controlled trial of paroxetine in children and adolescents with social anxiety disorder. Arch Gen Psychiatry. 2004;61:1153-1162.
73. Isolan L, Pheula G, Salum GA Jr, Oswald S, Rohde LA, Manfro GG. An open-label trial of escitalopram in children and adolescents with social anxiety disorder. J Child Adolesc Psychopharmacol. 2007;17: 751-760.

74. Schirman S, Kronenberg S, Apter A, et al. Effectiveness and tolerability of citalopram for the treatment of depression and anxiety disorders in children and adolescents: an open-label study. J Neural Transm. 2010;117:139-145.

75. Emslie G, Kratochvil C, Vitiello B, et al. Treatment for Adolescents with Depression Study (TADS): safety results. JAm Acad Child Adolesc Psychiatry. 2006;45:1440-1455.

76. March JS, Entusah AR, Rynn M, Albano AM, Tourian KA. A Randomized controlled trial of venlafaxine ER versus placebo in pediatric social anxiety disorder. Biol Psychiatry. 2007;62: 1149-1154.

77. Rynn MA, Riddle MA, Yeung PP, Kunz NR. Efficacy and safety of extended-release venlafaxine in the treatment of generalized anxiety disorder in children and adolescents: two placebo-controlled trials. $\mathrm{Am}$ J Psychiatry. 2007;164:290-300.

78. Rickels K, Schweizer E, DeMartinis N, Mandos L, Mercer C. Gepirone and diazepam in generalized anxiety disorder: a placebo-controlled trial. J Clin Psychopharmacol. 1997;17:272-277.

79. Schweizer E, Patterson W, Rickels K, Rosenthal M. Double-blind, placebo-controlled study of a once-a-day, sustained-release preparation of alprazolam for the treatment of panic disorder. Am J Psychiatry. 1993;150:1210-1215.

80. Simeon JG, Ferguson HB, Knott V, et al. Clinical, cognitive, and neurophysiological effects of alprazolam in children and adolescents with overanxious and avoidant disorders. $J$ Am Acad Child Adolesc Psychiatry. 1992;31:29-33.

81. Mancini C, Van Ameringen M, Bennett M, Patterson B, Watson C. Emerging treatments for child and adolescent social phobia: a review. J Child Adolesc Psychopharmacol. 2005;15:589-607.

82. Pine DS, Cohen P, Gurley D, Brook J, Ma Y. The risk for early-adulthood anxiety and depressive disorders in adolescents with anxiety and depressive disorders. Arch Gen Psychiatry. 1998;55:56-64.

83. Woodward LJ, Fergusson DM. Life course outcomes of young people with anxiety disorders in adolescence. $J$ Am Acad Child Adolesc Psychiatry. 2001;40:1086-1093.

84. Wittchen HU, Lieb R, Pfister H, Schuster P. The waxing and waning of mental disorders: evaluating the stability of syndromes of mental disorders in the population. Compr Psychiatry. 2000;41:122-132.

85. Last CG, Perrin S, Hersen M, Kazdin AE. A prospective study of childhood anxiety disorders. J Am Acad Child Adolesc Psychiatry. 1996;35:1502-1510.

86. Pine DS, Cohen P, Brook J. Adolescent fears as predictors of depression. Biol Psychiatry. 2001;50:721-724.

87. Stein MB, Fuetsch M, Muller N, Hofler M, Lieb R, Wittchen HU. Social anxiety disorder and the risk of depression: a prospective community study of adolescents and young adults. Arch Gen Psychiatry. 2001;58:251-256.

88. Beesdo K, Bittner A, Pine DS, et al. Incidence of social anxiety disorder and the consistent risk for secondary depression in the first three decades of life. Arch Gen Psychiatry. 2007;64:903-912.

89. Beesdo K, Pine DS, Lieb R, Wittchen HU. Incidence and risk patterns of anxiety and depressive disorders and categorization of generalized anxiety disorder. Arch Gen Psychiatry. 2010;67:47-57.

90. Foley DL, Goldston DB, Costello EJ, Angold A. Proximal psychiatric risk factors for suicidality in youth: the Great Smoky Mountains Study. Arch Gen Psychiatry. 2006;63:1017-1024.

91. Goldston DB, Daniel SS, Erkanli A, et al. Psychiatric diagnoses as contemporaneous risk factors for suicide attempts among adolescents and young adults: developmental changes. J Consult Clin Psychol. 2009;77:281-290.

92. Crum RM, Pratt LA. Risk of heavy drinking and alcohol use disorders in social phobia: a prospective analysis. Am J Psychiatry. 2001;158: 1693-1700. 
93. Zimmerman P, Wittchen HU, Hofler M, Pfister H, Kessler RC, Lieb R. Primary anxiety disorders and the development of subsequent alcohol use disorders: a 4-year community study of adolescents and adults. Psychol Med. 2003;33:1211-1222.

94. Ambrosini PJ. Historical development and present status of the schedule for affective disorders and schizophrenia for school-age children (K-SADS). J Am Acad Child Adolesc Psychiatry. 2000;39: 49-58.

95. Kessler RC, Wittchen HU, Abelson JM, et al. Methodological studies of the Composite International Diagnostic Interview (CIDI) in the US National Comorbidity Survey. Int $J$ Methods Psychiatr Res. 1998;7:171-185.

96. Reich W. Diagnostic interview for children and adolescents (DICA). $J$ Am Acad Child Adolesc Psychiatry. 2000;39:59-66.

97. Reich W. More on the DICA. J Am Acad Child Adolesc Psychiatry. 2000;39:14-15.

98. Angold A, Costello EJ. The Child and Adolescent Psychiatric Assessment (CAPA). J Am Acad Child Adolesc Psychiatry. 2000;39: 39-48.

99. Hodges K, Kline J, Stern L, Cytryn L, McKnew D. The development of a child assessment interview for research and clinical use. J Abnorm Child Psychol. 1982;10:173-189.
100. Hoehn-Saric E, Maisami M, Wiegand D. Measurement of anxiety in children and adolescents using semistructured interviews. $\mathrm{J} \mathrm{Am} \mathrm{Acad}$ Child Adolesc Psychiatry. 1987;26:541-545.

101. Reynolds CR, Richmond BO. What I think and feel: a revised measure of children's manifest anxiety. J Abnorm Child Psychol. 1978;6:271-280.

102. Spielberger CD. Manual for the State-Trait Anxiety Inventory for Children. Palo Alto, CA: Consulting Psychologists Press; 1973.

103. Beidel D, Turner S, Morris TL. A new inventory to assess childhood social anxiety and phobia: The Social Phobia and Anxiety Inventory for Children. Psychol Assess. 1995;7:73-79.

104. La Greca AM, Stone WL. The Social Anxiety Scale for ChildrenRevised: Factor structure and concurrent validity. J Clin Child Psychol. 1993;22:7-27.

105. La Greca AM, Lopez N. Social anxiety among adolescents: linkages with peer relations and friendships. J Abnorm Child Psychol. 1998;26:83-94.

\section{Publish your work in this journal}

Adolescent Health, Medicine and Therapeutics is an international, peer-reviewed, open access journal focusing on health, pathology, and treatment issues specific to the adolescent age group. All aspects of health maintenance, preventative measures and disease treatment interventions are addressed within the journal and practitioners from

\section{Dovepress}

all disciplines are invited to submit their work as well as healthcare researchers and patient support groups.. The manuscript management system is completely online and includes a very quick and fair peerreview system. Visit http://www.dovepress.com/testimonials.php to read real quotes from published authors.

Submit your manuscript here: http://www.dovepress.com/adolescent-health-medicine-and-therapeutics-journal 